Archived version from NCDOCKS Institutional Repository http://libres.uncg.edu/ir/asu/

\title{
Appalachľan
}

B O O NE, NORTH CAROLINA

\section{Visitability Surveillance, Prevalence, And Correlates In Florida}

\author{
By: Erin D. Bouldin, M.P.H., Elena M. Andresen, Ph.D., Sarah E. Bauer, M.P.H., Chelsea Whitney, \\ M.P.H., Claudia C. Tamayo, M.P.H., Jessica R. Schumacher, Ph.D., M.S., \\ and Allyson G. Hall, Ph.D., M.B.A., M.H.S.
}

\begin{abstract}
A primary means of social connection is visiting friends and families in their homes. Visitability is designing houses in a way that enables people to visit others' homes regardless of physical limitations or use of mobility assistive devices. The goals of this study were to develop a set of questions about visitability that could be used for surveillance and to assess the prevalence and correlates of visitability features in Florida. We added five questions to the 2011 Florida Behavioral Risk Factor Surveillance System ( $\mathrm{n}=12,399$ respondents) and used complementary log-log regression models to estimate the prevalence ratio of each visitability feature. The prevalence of visitability features in Florida homes was high for respondents with and without disabilities, though there was variation by visitability feature. A level entrance to the home and wide doorways were present in most respondents' homes (84.9\% and $86.2 \%$, respectively), while a main floor bathroom (59.6\%) and a zero-step entrance (45.4\%) were reported less commonly. People with a disability were less likely to report that their own home had doorways wide enough to accommodate a wheelchair compared to people without a disability ( $\mathrm{PR}=0.87,95 \% \mathrm{CI}$ : 0.80-0.95). Visitability features were less common in households with lower income and also in trailers or mobile homes than in detached single-family homes.
\end{abstract}

Bouldin, Erin D. et al. (2015). Visitability surveillance, prevalence, and correlates in Florida. Disability and Health Journal, Volume 8 , Issue 1 , 140 - 145. DOI: https://doi.org/10.1016/j.dhjo.2014.07.006. Publisher version of record available at: https://www.disabilityandhealthjnl.com/article/S1936-6574(14)00098-3/fulltext 


\section{Visitability Surveillance, Prevalence, And Correlates In Florida}

Erin D. Bouldin, M.P.H., Elena M. Andresen, Ph.D., Sarah E. Bauer, M.P.H., Chelsea Whitney, M.P.H., Claudia C. Tamayo, M.P.H., Jessica R. Schumacher, Ph.D., M.S., Allyson G. Hall, Ph.D., M.B.A., M.H.S.

\section{Abstract}

\section{Background}

A primary means of social connection is visiting friends and families in their homes. Visitability is designing houses in a way that enables people to visit others' homes regardless of physical limitations or use of mobility assistive devices.

\section{Objective}

The goals of this study were to develop a set of questions about visitability that could be used for surveillance and to assess the prevalence and correlates of visitability features in Florida.

\section{Methods}

We added five questions to the 2011 Florida Behavioral Risk Factor Surveillance System ( $n=12,399$ respondents) and used complementary log-log regression models to estimate the prevalence ratio of each visitability feature.

\section{Results}

The prevalence of visitability features in Florida homes was high for respondents with and without disabilities, though there was variation by visitability feature. A level entrance to the home and wide doorways were present in most respondents' homes (84.9\% and 86.2\%, respectively), while a main floor bathroom (59.6\%) and a zero-step entrance (45.4\%) were reported less commonly. People with a disability were less likely to report that their own home had doorways wide enough to accommodate a wheelchair compared to people without a disability (PR = 0.87, 95\% CI: 0.80-0.95). Visitability features were less common in households with lower income and also in trailers or mobile homes than in detached single-family homes.

\section{Conclusions}

The survey questions used in this study could be implemented in other states to measure and track visitability and monitor progress toward the Healthy People 2020 goal. Building or retrofitting homes to include visitability features could increase the participation and inclusion of people with disabilities in community life. 
Keywords:

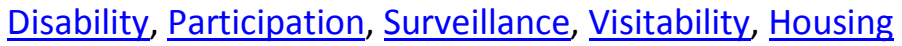

Individuals with a strong social support network and who are involved in their communities are less likely to experience depression, loneliness, and poor mental health. ${ }^{1} \underline{\underline{2}}$ A primary means of social connection is visiting friends and families in their homes. Visitability is designing houses in a way that enables people to visit others' homes regardless of physical limitations or use of mobility assistive devices. $\frac{3}{}$ The goal of visitability is not to build accessible homes specifically for individuals who need them, but to build all homes so that they have three features that allow anyone with mobility disability to use them: (1) a level path to a zero-step entrance, (2) doorways wide enough to accommodate a wheelchair, and (3) a bathroom on the main level of the home. ${ }^{3}, \underline{4}$ Visitability is a growing movement focusing on eliminating one form of environmental barrier, inaccessible housing, to participation.

While implementation and enforcement of the Americans with Disabilities Act (ADA) has improved the accessibility of public spaces, little progress has been made in the accessibility of private dwellings since the ADA does not address housing. .5 The inaccessibility of homes poses a challenge for maintaining social connectivity and a healthy society. As the population ages, the number of Americans needing mobility assistance in the form of wheelchairs, walkers, canes, or other assistive devices is expected to grow. $, \underline{4}, \underline{7}$ Smith and colleagues estimated a $91 \%$ probability that a new single-family home will either have a resident with a mobility disability or be visited by someone with a mobility disability. ${ }^{7}$ In recognition of this increasing need, a Healthy People 2020 objective is to increase the proportion of visitable US homes by $10 \%$ from the baseline estimate of $46.3 \%$ in $2007 .$.

Currently, however, little information about visitability features is available. The Healthy People 2020 benchmark utilizes the American Housing Survey (AHS) to assess whether homes have a zero-step entrance as a measure of visitability. In 2011, the AHS included the Housing Modification module which asked about home accessibility features and included questions about the presence of extra-wide doorways or hallways and an entry-level bathroom. ${ }^{9}, \underline{10}$ In 2004 and 2010, Montana included a single question about on its Behavioral Risk Factor Surveillance System Survey (BRFSS): "If a person who uses special equipment, such as a wheelchair, came to visit you, could they get into your house without being carried up steps or over other obstacles?" 11 Nearly 20\% of respondents in Montana reported their homes were visitable, with a slightly higher prevalence (22\%) among people with a disability than without (19\%).. However, this single question does not capture specific information about the interior of homes to assess whether they include the critical design elements of visitability (e.g., doorways wide enough to accommodate a wheelchair or bathroom on main level).

The goal of this study was to develop a set of questions about visitability that could be used for surveillance and to assess the prevalence and correlates of visitability features in Florida, the state with the second highest population over 65 and over 85 in 2010. $\underline{12}$ We also sought to assess whether disability or other demographic or housing characteristics were associated with the prevalence of visitability features in Florida homes. 


\section{Methods}

In 2010, the study team, part of the Florida Office on Disability and Health, developed a set of twelve questions on the topic of visitability, including the presence of visitable features in the home and the opinions of individuals about building new homes with visitable features. These questions were piloted on the Florida Consumer Confidence Index ( $\mathrm{FCCl}$ ), a random-digit dialed telephone survey, during two months in 2010: 775 Florida adults aged 18 and over participated (see Appendix). $\underline{13}$ After reviewing the pilot data, five visitability questions were selected for inclusion in the 2011 Florida Behavioral Risk Factor Surveillance System (BRFSS). While none of the piloted questions showed evidence that people did not understand the questions or were unwilling to answer them, we had limited funding available to add questions to the BRFSS. Therefore, we chose questions that related specifically to the physical design of homes rather than to people's attitudes about visitability. The questions included on the BRFSS were:

- (1)

How would you describe the building where you are living? Is it a mobile home or trailer, a one family house detached from any other house, a one family house attached to one or more houses on one or more sides, an apartment building, or other?

- (2)

Is there at least one entrance to your home that does not have a step or ledge?

- (3)

Is there a level, firm path from the road to your home's entrance?

- (4)

Is there at least one bathroom on the main floor of your home that someone using a wheelchair could enter and turn around?

- $(5)$

Are doorways on the main floor of your home wide enough for a wheelchair to fit through? This would be 32 inches wide or enough space for an average refrigerator to go through.

Details about the BRFSS, including sampling methodology and survey design, are available elsewhere..$^{14}$, 15 Briefly, the BRFSS is a random-digit dial landline and cellular telephone survey of non-institutionalized adults age 18 and older and is weighted to represent the population of each state on the basis of age, gender, and race/ethnicity, education level, marital status, and home ownership. The core BRFSS questionnaire includes questions about respondents' demographics and living situation. We classified respondent age into the following categories: $18-34,35-44,55-64,65-79$, and 80 or older. Household income is reported in categories on the BRFSS $(<\$ 15,000 ; \$ 15,000-24,999 ; \$ 25,000-49,999 ; \$ 50,000-$ 74,999 ; and $\geq \$ 75,000$ ) and these categories were maintained for the analysis, adding a missing indicator 
variable for respondents who did not know or refused to report their household income. CDC-defined disability was assessed with two questions: "Are you limited in any way in any activities because of physical, mental, or emotional problems?" and "Do you now have any health problem that requires you to use special equipment, such as a cane, a special bed, or a special telephone?" A respondent who answered affirmatively to at least one of these two questions was classified as having a disability.

Given the relatively high prevalence of each visitability feature among pilot respondents, we chose to use complementary log-log regression models to estimate the prevalence ratio in this study $\underline{\underline{ }}$ to avoid a likely violation of the rare outcome assumption that would have accompanied the use of traditional logistic regression model. We created four distinct models to identify respondent characteristics associated with each visitability feature. In each model, the visitability feature (zero step entrance, level path to the home's entrance, main floor bathroom, and doorways wide enough to accommodate a wheelchair) was the outcome, while disability status was the primary predictor variable of interest. Models adjusted for respondent age, gender, race/ethnicity, educational attainment, disability status, household income, and housing type. We chose the covariates based on their expected associations with housing quality and characteristics and with disability status. $\underline{17}, \underline{18}, \underline{19}$

We report the number and weighted frequencies of respondents who reported each visitability feature and results from the complementary log-log regression models, namely the prevalence ratio (PR) point estimates and 95\% confidence intervals (95\% CI) for the PR estimate. We calculated the $95 \%$ confidence interval as suggested by Penman and Johnson, by exponentiating the expression $(\widehat{\mathrm{PR}} \pm 1.96 * \mathrm{SE}(\widehat{\mathrm{PR}})) . \underline{16}$ All analyses used survey weights created via iterative proportional fitting (raking) $)^{15}$ and were conducted in SAS version 9.4. This study was reviewed by the University of Florida IRB-2 and considered to be exempt.

\section{Results}

In 2011, there were 12,399 BRFSS respondents in Florida, all of whom were asked the series of questions on disability and visitability. A level entrance to the home and wide doorways were present in most respondents' homes (84.9\% and $86.2 \%$, respectively), while a main floor bathroom $(59.6 \%)$ and a zerostep entrance (45.4\%) were reported less commonly (Table 1). The majority of respondents lived in a detached, single-family home $(70.8 \%)$ and most reported that they owned their home $(69.6 \%)$.

Table 1Number and percent reporting visitability features among all respondents, Florida Behavioral Risk Factor Surveillance System (BRFSS), 2011

\section{Variable}

\section{Housing description}

Type of housing

\section{Response category}

Number of responses
Weighted percent reporting 
Attached home (e.g. townhouse, duplex)

Multi-story building (e.g., condo, apartment)

Other

Own

Rent/Other
484

45

9268

2976

30.4

\section{Visitability features}

At least one entrance with no step or ledge

Level, firm path from road to entrance

Bathroom on main floor someone in a wheelchair could use Yes

Main floor doorways at least 32 inches wide

6.6

0.3 
0.28 for a zero step entrance, $\mathrm{PR}=0.94,95 \% \mathrm{Cl}: 0.83-1.07$ for a level path, $\mathrm{PR}=0.78,95 \% \mathrm{Cl}: 0.67-0.89$ for a main floor bathroom, and $\mathrm{PR}=0.70,95 \% \mathrm{Cl}$ : $0.61-0.80$ for wide doorways). A very small number of respondents who reported living in some other setting, making those point estimates unreliable.

Table 2Multivariate logistic regression models of visitability features associated with respondent and household characteristics, Florida Behavioral Risk Factor Surveillance System

(BRFSS), 2011

\begin{tabular}{|c|c|c|c|c|c|}
\hline \multirow{3}{*}{ Variable } & \multirow{3}{*}{ Response category } & \multicolumn{4}{|c|}{ Model outcome (visitability feature) } \\
\hline & & $\begin{array}{l}\text { Zero step } \\
\text { entrance }\end{array}$ & $\begin{array}{c}\text { Level } \\
\text { path }\end{array}$ & $\begin{array}{l}\text { Main floor } \\
\text { bathroom }\end{array}$ & $\begin{array}{c}\text { Wide } \\
\text { doorways }\end{array}$ \\
\hline & & $\begin{array}{l}\text { PR }(95 \% \\
\text { CI) }\end{array}$ & $\begin{array}{c}\text { PR } \\
(95 \% \\
\text { CI })\end{array}$ & PR (95\% CI) & $\begin{array}{l}\text { PR }(95 \% \\
\text { CI })\end{array}$ \\
\hline \multirow{6}{*}{ Respondent age } & $18-34$ & $\begin{array}{l}1.09(0.90- \\
1.32)\end{array}$ & $\begin{array}{l}0.81 \\
(0.69- \\
0.95)\end{array}$ & $\begin{array}{l}1.23(1.04- \\
1.45)\end{array}$ & $\begin{array}{l}0.94(0.80- \\
1.11)\end{array}$ \\
\hline & $35-44$ & $\begin{array}{l}1.01(0.85- \\
1.20)\end{array}$ & $\begin{array}{l}0.89 \\
(0.78- \\
1.03)\end{array}$ & $\begin{array}{l}1.07(0.92- \\
1.25)\end{array}$ & $\begin{array}{l}0.96(0.83- \\
1.10)\end{array}$ \\
\hline & $45-54$ & $\begin{array}{l}1.03(0.89- \\
1.19)\end{array}$ & $\begin{array}{l}0.85 \\
(0.76- \\
0.96)\end{array}$ & $\begin{array}{l}0.89(0.78- \\
1.03)\end{array}$ & $\begin{array}{l}0.88(0.77- \\
0.99)\end{array}$ \\
\hline & $55-64$ & Ref & Ref & Ref & Ref \\
\hline & $65-79$ & $\begin{array}{l}1.01(0.89- \\
1.16)\end{array}$ & $\begin{array}{l}1.12 \\
(1.01- \\
1.24)\end{array}$ & $\begin{array}{l}1.21(1.07- \\
1.36)\end{array}$ & $\begin{array}{l}1.12(1.00- \\
1.25)\end{array}$ \\
\hline & $80+$ & $\begin{array}{l}0.98(0.84- \\
1.15)\end{array}$ & $\begin{array}{l}1.33 \\
(1.16- \\
1.54)\end{array}$ & $\begin{array}{l}1.50(1.31- \\
1.73)\end{array}$ & $\begin{array}{l}1.17(1.01- \\
1.35)\end{array}$ \\
\hline \multirow{3}{*}{ Respondent gender } & Male & Ref & Ref & Ref & Ref \\
\hline & Female & $\begin{array}{l}0.95(0.87- \\
1.05)\end{array}$ & $\begin{array}{l}1.03 \\
(0.95- \\
1.12)\end{array}$ & $\begin{array}{l}0.95(0.87- \\
1.04)\end{array}$ & $\begin{array}{l}0.82(0.76- \\
0.89)\end{array}$ \\
\hline & White, non-Hispanic & Ref & Ref & Ref & Ref \\
\hline \multirow{2}{*}{$\begin{array}{l}\text { Respondent } \\
\text { race/ethnicity }\end{array}$} & Black, non-Hispanic & $\begin{array}{l}0.95(0.80- \\
1.14)\end{array}$ & $\begin{array}{l}1.17 \\
(1.01- \\
1.34)\end{array}$ & $\begin{array}{l}1.08(0.91- \\
1.27)\end{array}$ & $\begin{array}{l}1.26(1.07- \\
1.48)\end{array}$ \\
\hline & Any race, Hispanic & $\begin{array}{l}0.87(0.72- \\
1.05)\end{array}$ & $\begin{array}{l}1.00 \\
(0.86- \\
1.17)\end{array}$ & $\begin{array}{l}1.19(1.02- \\
1.39)\end{array}$ & $\begin{array}{l}1.37(1.17- \\
1.61)\end{array}$ \\
\hline
\end{tabular}




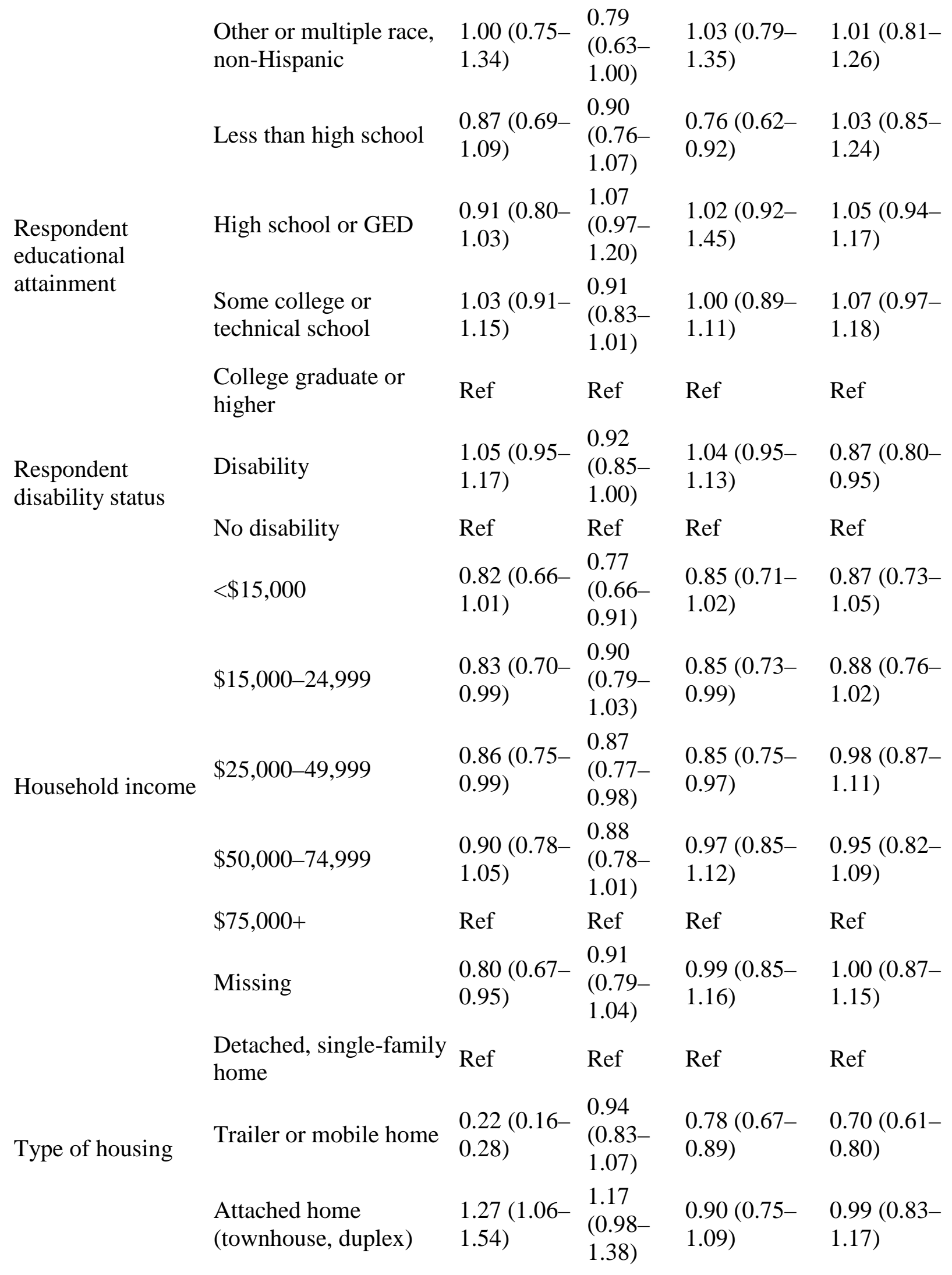




\begin{tabular}{|c|c|c|c|c|}
\hline $\begin{array}{l}\text { Multi-story building } \\
\text { (condominium, } \\
\text { apartment) }\end{array}$ & $\begin{array}{l}1.25(1.09- \\
1.43)\end{array}$ & $\begin{array}{l}0.92 \\
(0.81- \\
1.04)\end{array}$ & $\begin{array}{l}0.91(0.80- \\
1.03)\end{array}$ & $\begin{array}{l}1.17(1.04- \\
1.32)\end{array}$ \\
\hline Other & $\begin{array}{l}0.53(0.22- \\
1.23)\end{array}$ & $\begin{array}{l}0.51 \\
(0.24- \\
1.07)\end{array}$ & $\begin{array}{l}1.16(0.56- \\
2.40)\end{array}$ & $\begin{array}{l}3.00(1.99- \\
4.53)\end{array}$ \\
\hline
\end{tabular}

$P R$ : prevalence ratio, $\mathrm{Cl}$ : confidence interval, Ref: reference category $(P R=1.0)$.

There were no gender differences in the presence of visitability other than wide doorways, which women were less likely to report having in their homes ( $P R=0.82,95 \% \mathrm{Cl}: 0.76-0.89)$. There were no consistent differences in the presence of visitability features by race/ethnicity. Respondents who reported having Hispanic ethnicity were more likely to live in homes with a bathroom on the main floor $(P R=1.19,95 \% \mathrm{Cl}: 1.02-1.39)$ and homes with wide doorways $(\mathrm{PR}=1.37,95 \% \mathrm{Cl}: 1.17-1.61)$ compared to respondents who reported white race and non-Hispanic ethnicity.

\section{Discussion}

The presence of visitability features in Florida homes was generally high, regardless of disability status or other demographic characteristics. These results differ from Montana's, where overall respondentperceived visitability was low (about 20\%)..$\underline{11}$ We found no evidence that people with a disability are more likely to live in a home with any given visitability feature; in fact, they appear to be less likely to live in homes with a level path to the entrance and with wide doorways than their peers without disability. This difference could relate to the availability of affordable housing that contains visitable features. As noted in the National Council on Disability's assessment of progress since the implementation of the ADA in 1990, economic self-sufficiency continues to be an issue for people with disabilities, partly because of low employment rates. $\frac{5}{}$ Because disability itself often leads to unemployment we did not adjust for employment in our regression models. However, disparities in employment rates between people with and without disabilities may explain the lower prevalence of some visitability features among people living with disability.

One of the gains noted in the NCD's report on progress since the passage of the ADA was improved public attitudes about disability. ${ }^{-}$When we asked respondents to the $\mathrm{FCCl}$ as part of the visitability question pilot, over $70 \%$ of respondents said they were in favor of building new homes to be visitable and most would be somewhat or very willing to pay an additional $\$ 100$ to do so (data not shown). $\frac{13}{\text { The }}$ positive public opinion from our pilot study suggests housing development can accommodate visitability into new construction, and prior work in Pima, Arizona has indicated the difference in building costs to make homes visitable is about $\$ 100.4$ Nonetheless, efforts to expand requirements for federally-funded new single-family homes to be visitable (e.g., HR 2352: Eleanor Smith Inclusive Home Design Act of 2013) so far have not been successful. $\underline{20}$ As the population continues to age, basic home access will become increasingly important to promote social connectedness among people with mobility disabilities. $\underline{\underline{7}}$

While we assessed housing features associated with enabling a person with a disability to visit others' homes, we did not ask respondents with disabilities about their satisfaction with the features of the 
homes they visit, or whether they consider each of the visitability features assessed to be barriers to their visiting the homes of others. There is little existing literature on this topic, and no studies that we found assessed whether participation among people with disabilities is higher in neighborhoods with a high prevalence of visitable homes than in neighborhoods with less visitable housing. Future populationbased research might build on these prevalence data to better understand the impact of visitability features on people's behaviors and to quantify the potential impact of increasing visitability features on the participation of people with disabilities.

Also, a potential alternative explanation for the lower prevalence of some visitability features among people with disability is that people with a disability may be better able to judge whether doorways in homes are truly wide enough to accommodate a wheelchair rather than actual differences in housing characteristics. Future studies that assess the accuracy in reporting physical features of the home, such as hallway width or driveway grade, would be helpful in understanding whether differences exist between people with disabilities and people without disabilities.

The BRFSS provides population-level data on a variety of health events and is an established instrument to conduct surveillance on public health issues. The questions used in this study did not undergo formal cognitive testing that is used for questions approved as optional modules. States could therefore choose to use these questions as state-added BRFSS questions and could use only one or two questions or combine them into a single question, similar to the approach used by Seekins et al. in Montana. 11 Although these data come from a single state which may have a different type of housing stock than other places in the U.S., Florida's population includes a high proportion of older adults. Our findings may be informative for other states as they prepare for the increasing number of older adults that is occurring nationally.

\section{Conclusion}

With the prevalence of disability and the demand for accessible housing projected to increase in the coming decades, $\underline{6}, \underline{7}$ disparities in housing could result in disparities in community participation for people with disabilities. Building or retro-fitting homes to include visitability features could increase the participation and inclusion of people with disabilities in community life. We found that many Florida homes have features that make them visitable. These features vary somewhat by disability and household income and, in some cases, by housing type but not by other characteristics. The survey questions used in this study could be implemented in other states and other surveillance systems to measure and track visitability and to monitor progress toward the Healthy People 2020 goal to increase the proportion of visitable US homes by $10 \%$.

\section{Appendix}




\section{Visitability Questions Pilot Tested on Florida Consumer Confidence Index survey in 2010}

Note: Questions 1-5 were subsequently included on the 2011 Florida BRFSS

1. In what type of house or building do you live?

A detached, single-family home

A trailer or mobile home

An attached home like a townhouse or a duplex

A multi-story building like a condominium or apartment

Other (

Don't know/not sure

Refused

2. Is there at least one entrance to your home that does not have a step or ledge?

Yes

No

Don't know/not sure

Refused

3. Is there a level, firm path from the road to your home's entrance?

Yes

No

Don't know/not sure

Refused

4. Is there at least one bathroom on the main floor of your home that someone using a wheelchair could enter and turn around?

Yes

No

Don't know/not sure

Refused

Ask only if respondent said "Yes" to Q4

5. Does the door on that bathroom swing into the bathroom?

Yes

No

Don't know/not sure

Refused

Ask only if respondent said "Yes" to Q4

6 . Is there a cabinet under the sink in that bathroom?

Yes

No

Don't know/not sure 
Refused

7. Are doorways on the main floor of your home wide enough for a wheelchair to fit through? This would be 32 inches wide or enough space for an average refrigerator to go through.

Yes

No

Don't know/not sure

Refused

Ask only if respondent said "Yes" to Q2, Q4, or Q7.

8. How would you say the features of your home - the no-step entrance, bathroom on the main floor, or wide doorways - affect your quality of life? Do they...

Increase your quality of life

Decrease your quality of life

Make no change in your quality of life

Don't know/not sure

Refused

9. The preceding questions have asked about a concept called "visitability" or the ability for people of all ages and physical abilities to visit other people's homes. Would you be in favor of building new homes with at least one entry without steps, an accessible bathroom on the main floor, and wide hallways?

Yes

No

Don't know/not sure

Refused

10. If you were purchasing a new home, how much additional money would you be willing to pay to make the home visitable?

No extra money $(\$ 0)$

Up to $\$ 100$ extra

$\$ 100-499$ extra

$\$ 500-999$ extra

$\$ 1,000$ or more extra

Don't know/not sure

Refused

11. In Florida, building a new home that is "visitable" would add an estimated $\$ 100$ to the cost of the home. How willing would you be to pay an extra $\$ 100$ for a new home that was visitable?

(Read answer choices)

Very willing to pay

Somewhat willing to pay

Somewhat unwilling to pay

Very unwilling to pay

Don't know/not sure

Refused 
12. Is there a sidewalk in front of your home on one or both sides of the street?

Yes

No

Don't know/not sure

\section{References}

1. Seeman, T.E. Social ties and health: the benefits of social integration. Ann Epidemiol. 1996; 6: 442-451

2. Kawachi, I. and Berkman, L.F. Social ties and mental health. J Urban Health. 2001; 78: 458-467

3. Concrete Change. Every New Home Visitable. (Available at:) (Accessed 30.05.14); 2012 http://concretechange.org/

4. Maisel, J., Smith, E., and Steinfeld, E. Increasing Home Access: Designing for Visitability. (Washington, D.C. Available at:) (Accessed 30.05.14); 2008 http://assets.aarp.org/rgcenter/il/2008 14 access.pdf

5. National Council on Disability. The Impact of the Americans With Disabilities Act: Assessing the Progress Toward Achieving the Goals of the ADA. (Available at:) (Accessed 30.05.14); 2007 http://www.ncd.gov/publications/2007/07262007\#toc1

6. Committee on Disability in America, Board on Health Sciences Policy, Institute of Medicine. ([Print])in: M.J. Field, A.M. Jette (Eds.) The Future of Disability in America. National Academies Press, Washington, DC; 2007

7. Smith, S.K., Rayer, S., and Smith, E.A. Aging and disability: Implications for the housing industry and housing policy in the United States. J Am Plann Assoc. 2008; 74: 289-306 
8. U.S. Department of Health and Human Services (US DHHS). Office of Disease Prevention and Health Promotion. Healthy People 2020: Disability and Health. Washington, DC. Available at: http://www.healthypeople.gov/2020/topicsobjectives2020/overview.aspx?topicid=9; Accessed 30.05.14.

9. US Department of Housing \& Urban Development Office of Policy Development and Research. Codebook for the American Housing Survey, Public Use File: 1997-2011, Version 2.1. (Available at:) (Accessed 30.05.14); March 2013

http://www.census.gov/programs-surveys/ahs/tech-documentation/ahs-codebook.html

10. American Housing Survey for the United States: 2011. Current Housing Reports. (Available at:) (Accessed 30.05.14); September 2013

http://www.census.gov/content/dam/Census/programs-surveys/ahs/data/2011/h150-11.pdf

11. Seekins, T., Traci, M.A., Cummings, S., Oreskovich, J., and Ravesloot, C. Assessing environmental factors that affect disability: establishing a baseline of visitability in a rural state. Rehabil Psychol. 2008; 53: 80-84

12. Werner, C.A. 2010 Census Briefs: The Older Population: 2010. (Available at:) (Accessed 30.05.14); 2011

http://www.census.gov/prod/cen2010/briefs/c2010br-09.pdf

13. Bouldin, E.D., Andresen, E.M., Cannell, M.B. et al. Visitability in Florida: Results From a Pilot Study. (Available at:) (Accessed 30.05.14)Florida Office on Disability and Health, ; 2011 http://fodh.phhp.ufl.edu/files/2011/05/Visitability Pilot Results final 09-05-11.pdf

14. Mokdad, A. The behavioral risk factor surveillance system: past, present and future. Annu Rev Public Health. 2009; 30: 43-54

15. Pierannunzi, C., Town, M., Garvin, W., Shaw, F.E., and Balluz, L. Methodologic changes in the Behavioral Risk Factor Surveillance System in 2011 and potential effects on prevalence estimates. MMWR Morb Mortal Wkly Rep. 2012; 61: 410-413 
16. Penman, A.D. and Johnson, W.D. Complementary log-log regression for the estimation of covariate-adjusted prevalence ratios in the analysis of data from cross-sectional studies. Biom J. 2009; 51: 433-442

17. CDC Health Disparities and Inequalities Report - United States, 2011. MMWR. 2011;

18. Krieger, J. and Higgins, D.L. Housing and health: time again for public health action. Am J Public Health. 2002; 92: 758-768

19. Narine, L. and Shobe, M.A. Making sense of housing disparities research: a review of health and economic inequities. Soc Work Public Health. 2014; 29: 35-41

20. HR 2342 - Eleanor Smith Inclusive Home Design Act of 2013. Available at: http://beta.congress.gov/bill/113th-congress/house-bill/2352; Accessed 30.05.14.

Conflict of interest statement: None of the authors have any conflict of interest or relevant financial interests to report.

Prior presentations and publication: This manuscript has not been published or submitted in peerreviewed form elsewhere. We created a report for lay audiences and the Florida Department of Health using the data as part of the grant that supported the work, the CDC Disability and Health State Program. The report is available online and is cited in the manuscript. The data were presented at the annual BRFSS conference last year as a poster by co-author Bauer.

This work was supported by CDC U59DD000273-04. EMA was funded in part by the Oregon Office on Disability and Health for this research (CDC U59DD00094201). This material is the result of work supported by resources from the VA Puget Sound Health Care System, Seattle, Washington.

Disclaimer: The views expressed in this article are those of the authors. 
